\title{
A Numerical Study on the Impact of High-Frequency Winds on the Peru Upwelling System during 2014-2016
}

\author{
Linhui Wang ${ }^{1}$, Huiwang Gao ${ }^{1,2}$, Jie Shi ${ }^{1,2}$ and Lian Xie ${ }^{3, *}$ \\ 1 Key Laboratory of Marine Environment and Ecology, Ocean University of China, Ministry of Education, \\ Qingdao 266100, China; forestwlh@gmail.com (L.W.); hwgao@ouc.edu.cn (H.G.); shijie@ouc.edu.cn (J.S.) \\ 2 Laboratory for Marine Ecology and Environmental Sciences, Qingdao National Laboratory for Marine \\ Science and Technology, Qingdao 266071, China \\ 3 Department of Marine, Earth and Atmospheric Sciences, North Carolina State University, Box 8208, Raleigh, \\ NC 27695-8208, USA \\ * Correspondence: lian_xie@ncsu.edu
}

Received: 7 May 2019; Accepted: 21 May 2019; Published: 25 May 2019

\begin{abstract}
The contribution of high-frequency wind to the Peruvian upwelling system during 2014-2016 was studied using the Regional Ocean Modeling System (ROMS), forced by four different temporal resolution (six-hourly, daily, weekly, and monthly) wind forcing. A major effect of the high-frequency wind is its warming of the water at all depths along the Peruvian coast. The mechanism for the temperature changes induced by high-frequency wind forcing was analyzed through heat budget analysis, which indicated a three-layer structure. Vertical advection plays a leading role in the warming of the mixed layer $(0-25 \mathrm{~m})$, and enhanced vertical mixing balances the warming effect. Analysis suggests that around the depths of 25-60 m, vertical mixing warms the water by bringing heat from the surface to deeper depths. In waters deeper than $60 \mathrm{~m}$, the effect of vertical mixing is negligible. The differences among the oceanic responses in the sensitivity experiments suggest that wind forcing containing variabilities at higher than synoptic frequencies must be included in the atmospheric forcing in order to properly simulate the Peru upwelling system.
\end{abstract}

Keywords: high-frequency wind; diurnal; upwelling; vertical velocity

\section{Introduction}

The Peruvian coast is one of the most productive eastern boundary upwelling systems in the world, which supports important local fisheries [1]. Upwelling can bring cooler and nutrient-rich subsurface water to the surface, playing a key role in biological activity. Due to the Andes Mountains along the Peruvian coast, the subtropical high drives the southeasterly wind parallel to the coast throughout the year, which generates strong off-shore Ekman transports in the upper ocean, inducing the coastal upwelling along the Peruvian coast.

Air-sea interactions can facilitate scale interactions in ocean circulation, creating oceanic variability [2]. Some studies have paid attention to the influence of high-frequency wind on ocean dynamics. High-frequency wind can enhance the turbulent diffusion in the ocean surface layer [3], deepen the mixed layer [4], increase downward heat flux [5], and cool the sea surface temperature (SST) $[6,7]$. The impact of the high-frequency wind is associated with the upper ocean dynamics. For example, the effect of diurnal wind forcing on SST is closely related to the depth of the mixed layer $[7,8]$. Lee and Liu [9] showed that the effects of high-frequency wind on the ocean in the mid- to high-latitude regions are primarily derived from enhanced vertical mixing, whereas such effects in the tropical oceans are mainly derived from wind-induced advection. 
The upwelling systems are affected by air-sea interactions over a wide range of spatio-temporal scales, from large scales $\left(>10^{4} \mathrm{~km}\right.$ and inter-annual) to meso- and synoptic scales $\left(10^{1}-10^{3} \mathrm{~km}\right.$ and $<10^{2}$ day). For example, El Niño events lead to thermocline and nutricline deepening due to the coastal-trapped waves, as well as a significant decrease in nutrient content and biological productivity [10]. The Central Pacific El Niño and Eastern Pacific El Niño show different rectification on the mean state of Peru upwelling conditions through a contrasted equatorial Kelvin wave [11]. Local atmospheric forcing may also play an important role in the upwelling dynamics. The diurnal upwelling driven by sea breeze can lead to large fluctuations in temperature [12,13]. The coastal upwelling front propagates up and down the coast due to modulation by diurnal wind forcing [14], and internal waves and inertial oscillations can be excited by sea breeze $[15,16]$. Despite the great deal of attention paid to the local-scale oceanic variability, the impact of local-scale wind on the mean state and low-frequency variability of the upper ocean is still not well understood.

The aim of this study was to document the impact of high-frequency (six-hourly) wind on the variability of ocean temperature and the upwelling system along the Peruvian coast by simulating the Peruvian upwelling system using a high-resolution regional model, and analyzing the causes of temperature changes through heat budget.

The rest of the paper is organized as follows. The model configuration and the design of sensitivity experiments are presented in Section 2. Section 3 documents the differences of the temperature, the variability, and mean state of the upwelling system due to the high-frequency wind. Section 4 presents a heat budget analysis on temperature changes caused by high-frequency wind. The last section provides a summary of the results.

\section{Model Configuration, Sensitivity Experiments, and Data}

\subsection{Model Configuration}

In this study, the Regional Ocean Modeling System (ROMS) (UCLA, Los Angeles, CA, USA) [17] was used to simulate the Eastern Tropical Pacific circulation extending from $15^{\circ} \mathrm{S}$ to $20^{\circ} \mathrm{N}$ and from $75^{\circ} \mathrm{W}$ to $105^{\circ} \mathrm{W}$ (Figure 1a). Figure $1 \mathrm{~b}$ shows the Peruvian coast with a narrow shelf, sharp slope, and more than $3500 \mathrm{~m}$ depth basin. ROMS is a free surface, hydrostatic, primitive equations ocean model using stretched, topography-following sigma coordinates. The model has $302 \times 352$ grid points with a horizontal resolution of $0.1^{\circ}$ and 40 vertical levels. The topography, derived from ETOPO1 [18] $\left(1 / 60^{\circ}\right.$ global relief model that integrates land topography and ocean bathymetry), was smoothed to reduce pressure gradient errors [19].

At the lateral boundaries, the monthly $0.5^{\circ}$ resolution reanalysis ocean data from Climate Forecast System Research version 2 (CFSRv2, https://rda.ucar.edu/datasets/ds094.0/) provide the horizontal velocity, sea level, temperature, and salinity boundary data. At the air-sea interface, we used the six-hourly $0.5^{\circ}$ resolution atmospheric fields from CFSRv2, including surface heat fluxes, short wave radiation, fresh water fluxes, and wind stresses. Due to the biases in the heat fluxes, a heat correction is usually applied to avoid long-term drifts in the SST in regional ocean modeling. The relaxation parameter in this study was assigned a value of $35 \mathrm{~W} / \mathrm{m}^{2} / \mathrm{K}$ [20]. Initial conditions came from the January 2013 CFSRv2 monthly reanalysis data. The model was spun up for six years, forced by the repeating atmosphere and ocean data of the year 2013. Exp_control, the control run experiment, started from the equilibrium solutions on 1 December 2013 and performed a three-year oceanic simulation from 1 December 2013 to 31 December 2016.

\subsection{Sensitivity Experiments}

We first averaged the six-hourly wind stresses in time at intervals of day, week, and month, respectively, resulting in four different time series of wind stress fields. A set of four sensitivity experiments (named Exp_6hour, Exp_day, Exp_week, and Exp_month) were performed to analyze the response of Peru upwelling to atmospheric winds at above four different temporal resolutions from 
2014 to 2016, and all the air-sea boundary forcing and lateral boundary forcing were kept identical except for the wind stresses. In these four sensitivity experiments, the heat correction was turned off to avoid the artificial biases in temperature due to relaxation.

\subsection{Data}

The following observation data and reanalysis data were used to validate the simulation results:

(1) The temperature along the Peruvian coast is described through monthly Global Ocean Reanalysis and Simulation (GLORYS12V1) potential temperature, an eddy-resolving reanalysis ocean data with a $1 / 12^{\circ}$ horizontal resolution and 50 vertical levels, from 2014 to 2016 (http://marine.coperni cus.eu/).

(2) Archiving, Validation, and Interpretation of Satellites Oceanographic Data (AVSIO) provides daily $1 / 3^{\circ}$ horizontal resolution geostrophic current fields, which are distributed by the Copernicus Marine and Environment Monitoring Service (http://www.marine.copernicus.eu).

(3) Optimum Interpolation Sea Surface Temperature (OISST) was used in this study, which provides daily $0.25^{\circ}$ horizontal resolution SST fields (https://www.esrl.noaa.gov/psd/).

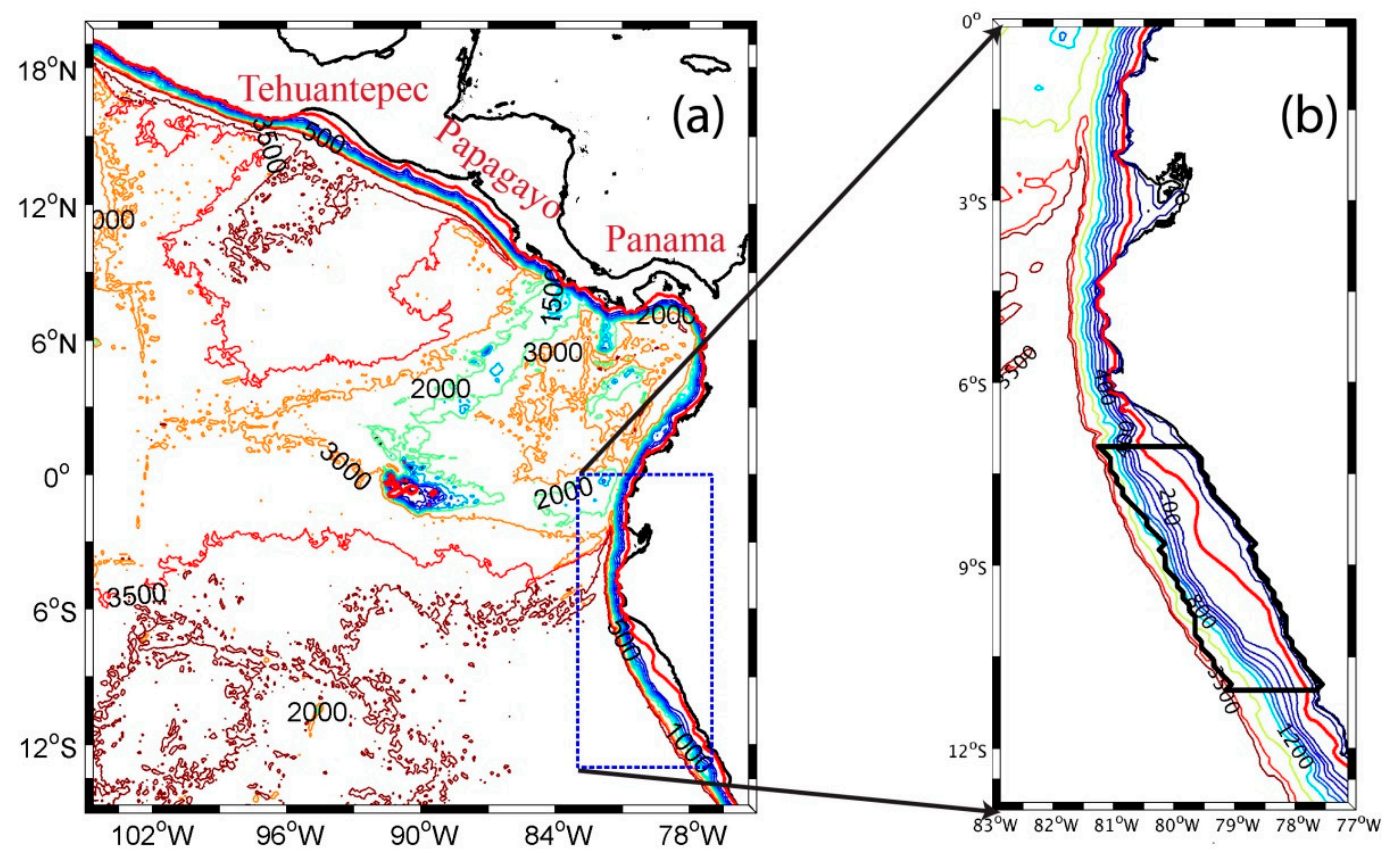

Figure 1. (a) Bathymetry of the Eastern Tropical Pacific adopted in all simulations. (b) Zoomed-in maps highlighting the nearshore study domain along the Peruvian coast (in meters; the black box marks the upwelling domain from $7^{\circ} \mathrm{S}$ to $11^{\circ} \mathrm{S}$ and $150 \mathrm{~km}$ away from the coast. It will be referred to as the "sampling area" hereafter).

\section{Results}

\subsection{Temperature Sensitivity to High-Frequency Wind}

Figure 2 displays the 2014-2016 three-year mean SST and surface geostrophic current in the Eastern Tropical Pacific from the observations (OISST and AVSIO, Figure 2a) and the simulation results (Exp_control, Figure 2b and Exp_6hour, Figure 2c). The Eastern Tropical Pacific warm pool, where SST is more than $27.5^{\circ} \mathrm{C}$, is located north of the equator. SST in the regions under the Tehuantepec Jet, Papagayo Jet, and Panama Jet is $2-3{ }^{\circ} \mathrm{C}$ lower than that of the surrounding area. The waters of the equatorial cold tongue and Peru Current are relatively colder due to the equatorial upwelling and Peruvian upwelling. The model can simulate realistic patterns of mean SST and surface circulation. The comparison of the Exp_control and the Exp_6hour shows that, turning off heat correction, the 
biases of heat fluxes resulted in a $1-2{ }^{\circ} \mathrm{C}$ increase in the mean SST in the warm pool, but had relatively little effect on the mean SST south of the equator.

(a) Observation

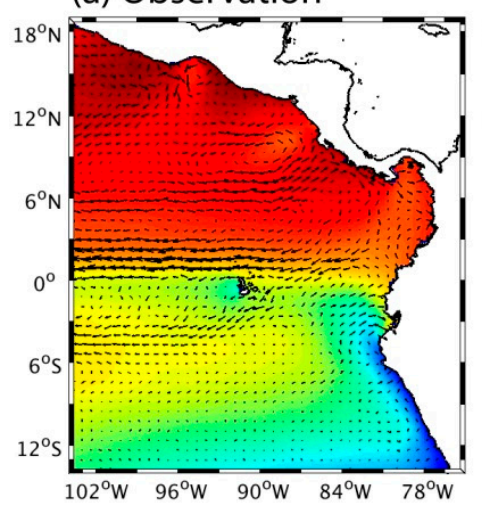

(b) Exp_control

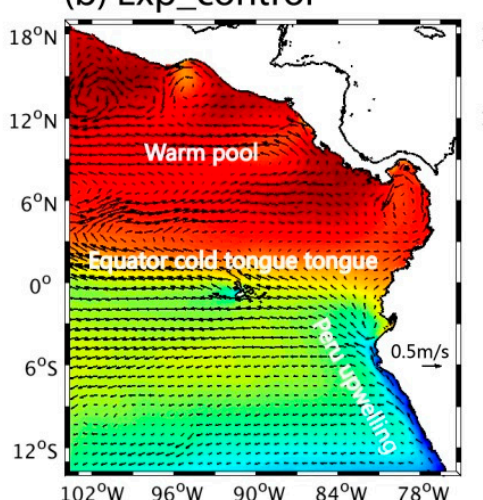

(c) Exp_6hour

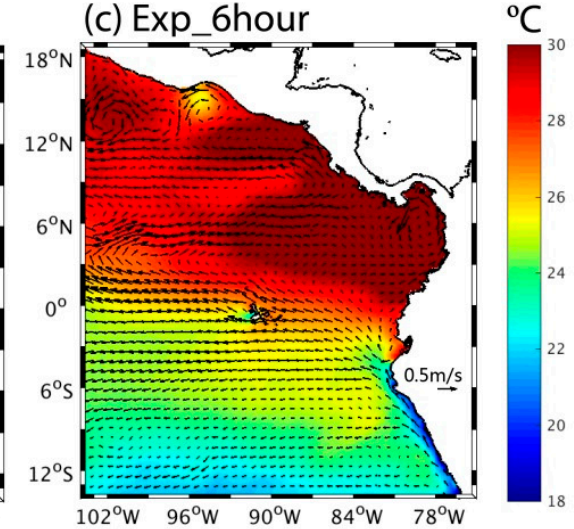

Figure 2. Three-year (2014-2016) mean SST and geostrophic current from (a) observations (OISST and AVSIO), (b) model output (Exp_control) with heat correction, and (c) model output (Exp_6hour) without heat correction.

Figure 3 shows the differences of mean SST between Exp_6hour and Exp_day, Exp_6hour and Exp_week, and Exp_6hour and Exp_month. SST values in most regions of the warm pool decreased, which is consistent with the studies of Chen et al. [21] and Zhou et al. [7] which indicated that the enhanced mixing due to high-frequency wind cooled SST. However, over most regions of the equatorial cold tongue and Peruvian upwelling, SST increased under the influence of high-frequency wind, indicating that there is perhaps another controlling factor. As the temporal resolution of wind decreased, the differences in SST increased. The difference between Exp_6hour and Exp_month along the Peruvian coast was up to $0.5^{\circ} \mathrm{C}$.

(a) Exp_6hour - Exp_day

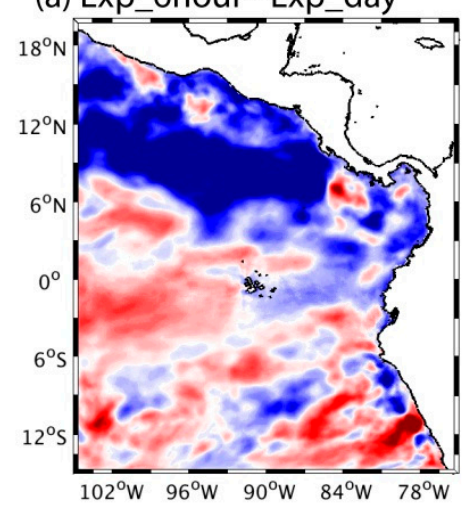

(b) Exp_6hour - Exp_week

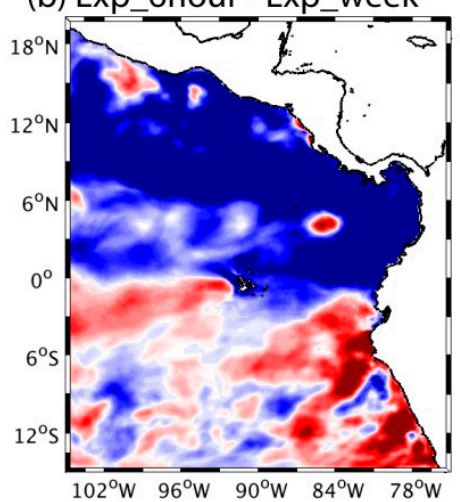

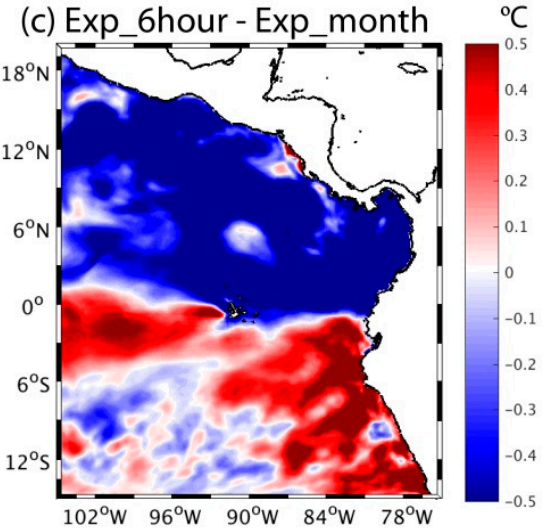

Figure 3. The three-year mean SST differences between (a) Exp_6hour and Exp_day, (b) Exp_6hour and Exp_week, and (c) Exp_6hour and Exp_month.

The coastline of Peru is rather straight, and the spatial distribution of SST and current is parallel to the coastline. Therefore, the mean temperature in the sampling area (depicted by the black box, Figure $1 b$ ) at the same depth was used to quantify the temperature of the Peruvian upwelling system. Figure 4a shows the time-depth cross section of the temperature along the Peruvian coast from the reanalysis data GLORY12V1, and Figure 4b,c shows the simulation results from Exp_control and Exp_6hour. The model could reasonably capture the temperature evolution of the Peruvian upwelling system, and no significant differences were found in the temperature simulations between Exp_control and Exp_6hour. The temperature along the Peruvian coast increased in austral summer 
(December to February) due to the absorption of strong shortwave radiation. In austral autumn (March to May) the Peru Counter-Current led to a deeper thermocline and warmer mixed-layer water. The temperature in austral winter (June to August) decreased due to reduced radiative heating and the Peru Counter Current. Peru upwelling has a close connection with El Niño-Southern Oscillation (ENSO) variability [11,22]. A warmer temperature relative to 2014 year appeared during the 2015-2016 El Niño events.

(a) GLORY12v1
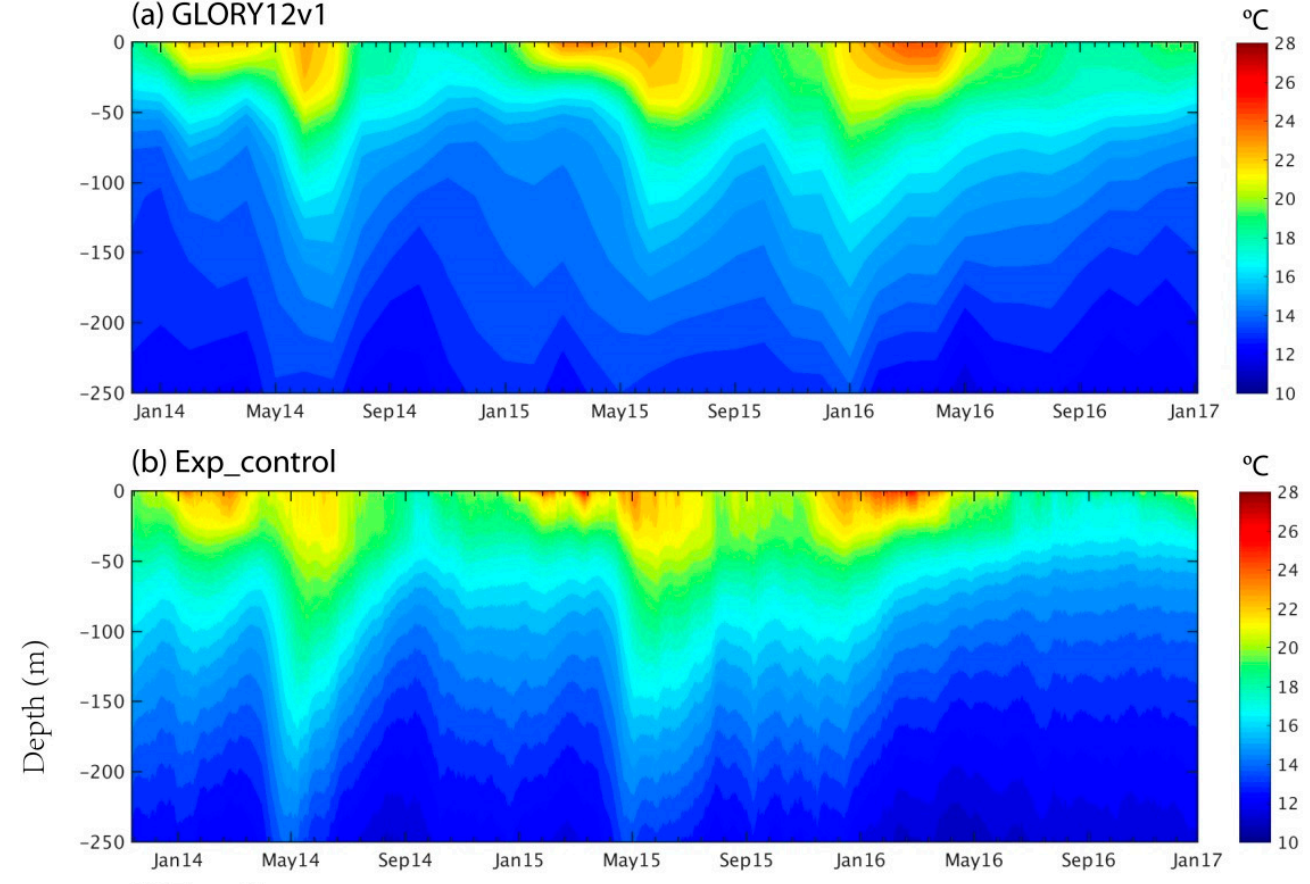

(c) Exp_6hour $\quad{ }^{\circ} \mathrm{C}$
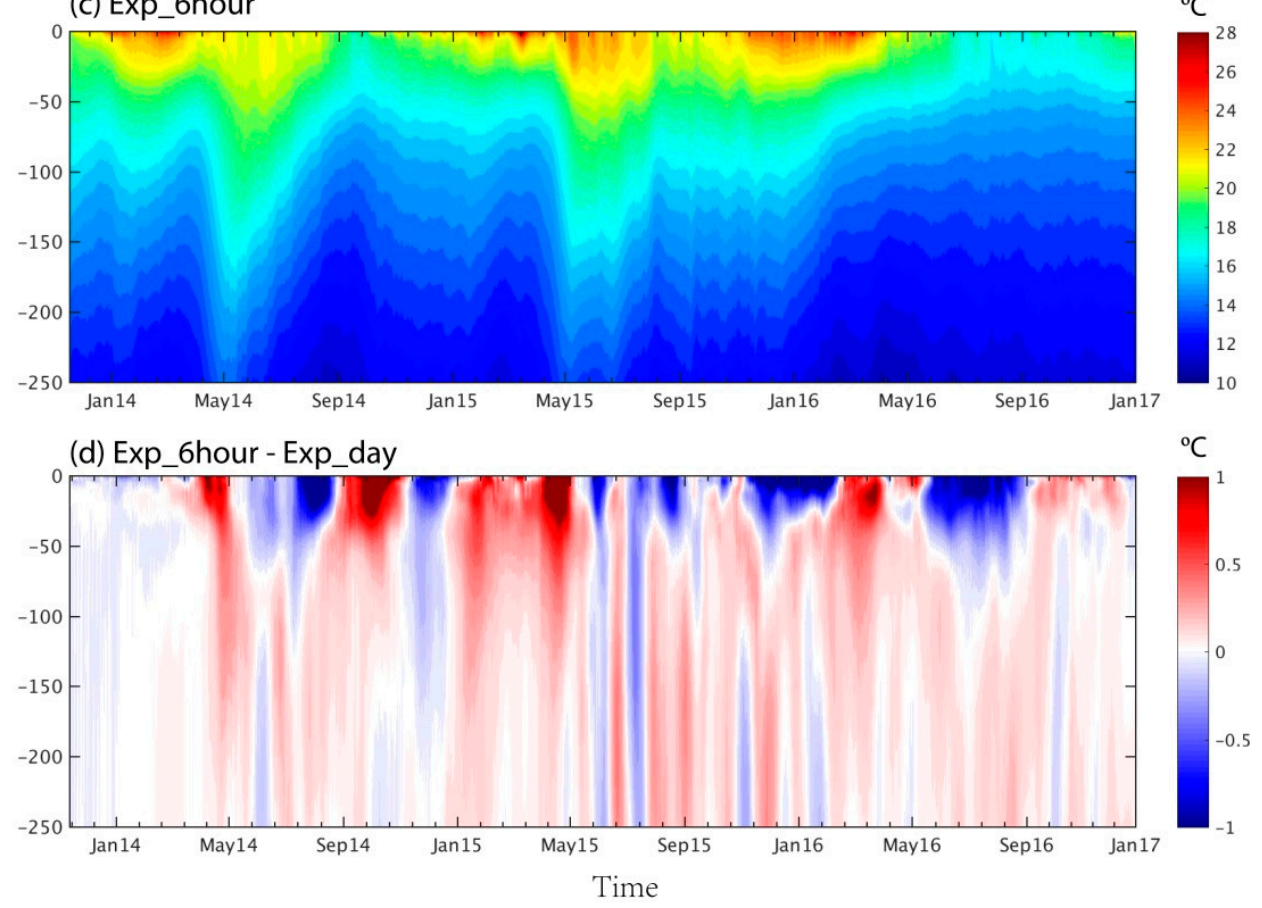

Figure 4. Temperature along the Peruvian coast from (a) GLORY12V1, (b) Exp_control, and (c) Exp_6hour. (d) The temperature differences between Exp_6hour and Exp_day.

Figure $4 \mathrm{~d}$ displays the differences in temperature along the Peruvian coast between Exp_6hour and Exp_day, which were similar to those between Exp_6hour and Exp_week, and Exp_6hour and 
Exp_month (not shown). The impact of high-frequency wind on surface temperature showed an alternation of cooling and warming. During the austral autumn (April to May) and spring (September to October), there were often positive biases. Significant warming occurred in September 2014 and May 2015, exceeding $1.5^{\circ} \mathrm{C}$. Negative biases followed the warm biases (e.g., austral winter, June to July and austral summer, November to December). The temperature differences under the mixed layer due to the high-frequency wind showed warming most of the time.

\subsection{Impact of High-Frequency Wind on the Upwelling}

We averaged the vertical velocities in the sampling area (Figure $1 \mathrm{~b}$ ) at $50 \mathrm{~m}$ (Figure 5). The vertical velocities were positive most of the time, and the three-year mean was $0.72 \mathrm{~m} /$ day. The upwelling weakened during the austral autumns of 2014 and 2015. The vertical velocities were about $0.1 \mathrm{~m} /$ day in May 2014 and $-0.28 \mathrm{~m} /$ day in May 2015. Meanwhile, temperature showed significant warming (Figure 4a). In austral winter, upwelling strengthened and temperature decreased. Despite the different temporal scales of wind forcing, the long-term trend of vertical velocities remained similar, while the fluctuations of vertical velocities weakened significantly. The Pearson similarity coefficients of vertical velocities (50 m) between Exp_6hour and Exp_day were as large as 91\%, while the similarity between Exp_week and Exp_6hour as well as Exp_month and Exp_6hour decreased to 37\% and $25 \%$, respectively.

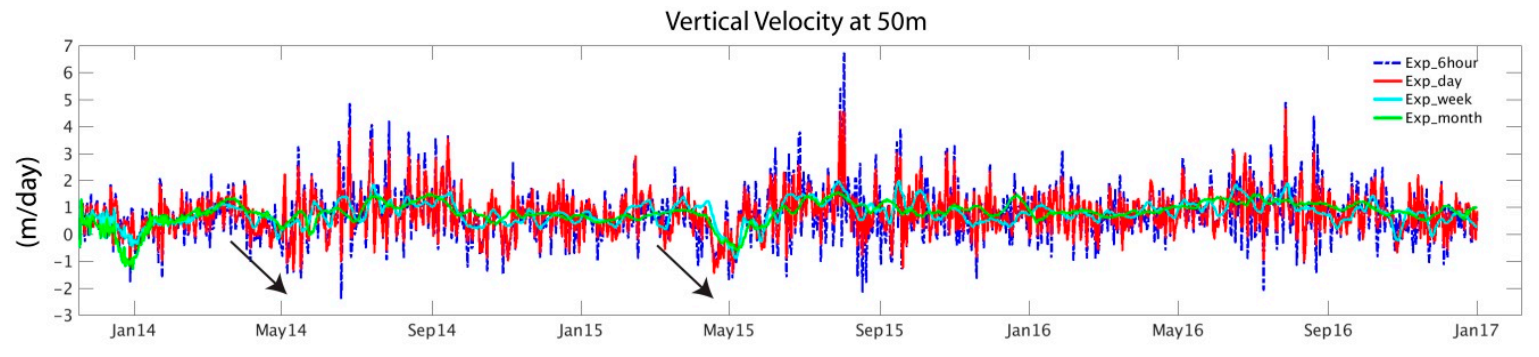

Figure 5. Time evolution of the vertical velocities in the Peruvian upwelling at $50 \mathrm{~m}$ (Note: positive means upwelling and negative means downwelling).

The power spectra of the vertical velocities in the sampling area (Figure 1b) are shown in Figure 6 as a function of depth. The vertical velocity spectra of the upper water column indicate that with increasing water depth, the vertical velocities displayed enhanced variance within the short-period band, such as $2-3$ days, 5-6 days, 10-18 days, 40-50 days, and 160-240 days. The periodic signals of vertical velocities are mainly derived from near-inertial waves (2-3 days, [23]), subtidal fluctuations (4-20 days, [24]), coastal-trapped Kelvin waves (35-60 days, [25]; 60-70 days, [26]), and semi-annual and annual variations. Figure 7 shows the spectra of different temporal scales of wind near the Peruvian coast. The temporal smoothing of wind stress resulted in the reduction of high-frequency oscillation and less impact on low-frequency signals. There were significant differences between the spectra of wind stress and vertical velocities, suggesting that the fluctuations of vertical velocities are mainly derived from the free ocean waves, not directly tied to the wind-forced waves. Upon eliminating the diurnal cycle of wind, the near-inertial wave (2-3 days) of vertical velocities weakened. The waves with periods of 5-6 days and 10-18 days significantly decreased without the synoptic and diurnal wind forcing. The results of Exp_month were similar to Exp_week in that the low-frequency variances decreased further. The synoptic and sub-synoptic variances of the wind stresses provided the most energy to the near-inertial, weekly, and bi-weekly (i.e., 2-3 days, 5-6 days, and 10-18 days) oceanic fluctuations, in keeping with the findings of Dewitte et al. [25], which analyzed the covariability between wind stress and SST data, and revealed that the 10-25day SST variability was closely related to the Ekman dynamics of wind stress. Jouanno et al. [27] analyzed a set of simulations of Yucatan upwelling and showed a 6-10-day mode of variability related to coastal waves derived from wind forcing. 


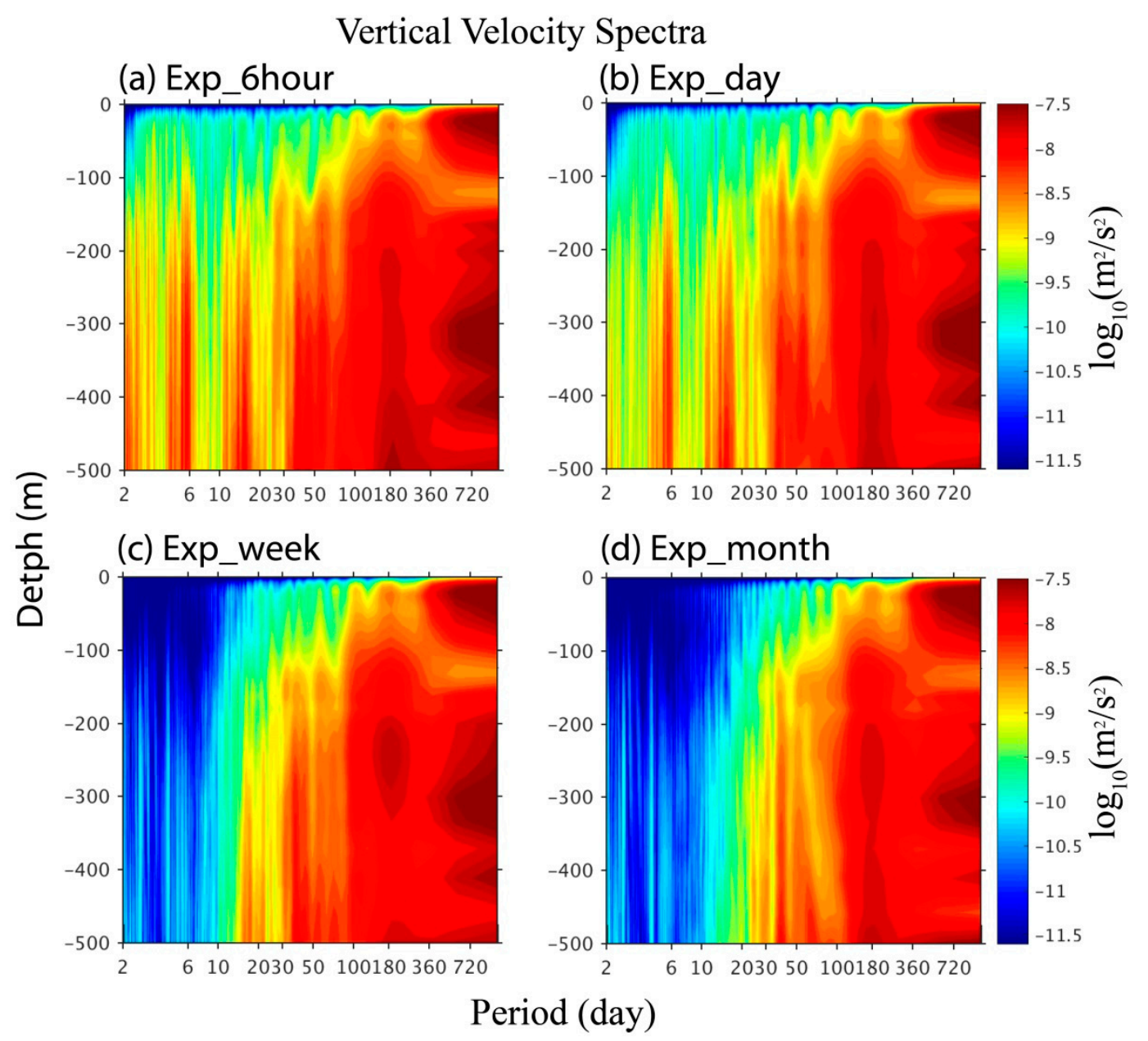

Figure 6. The power spectra of vertical velocities from (a) Exp_6hour, (b) Exp_day, (c) Exp_week, and (d) Exp_month.

(a) Zonal wind stress $\left(80^{\circ} \mathrm{W}, 9^{\circ} \mathrm{S}\right)$

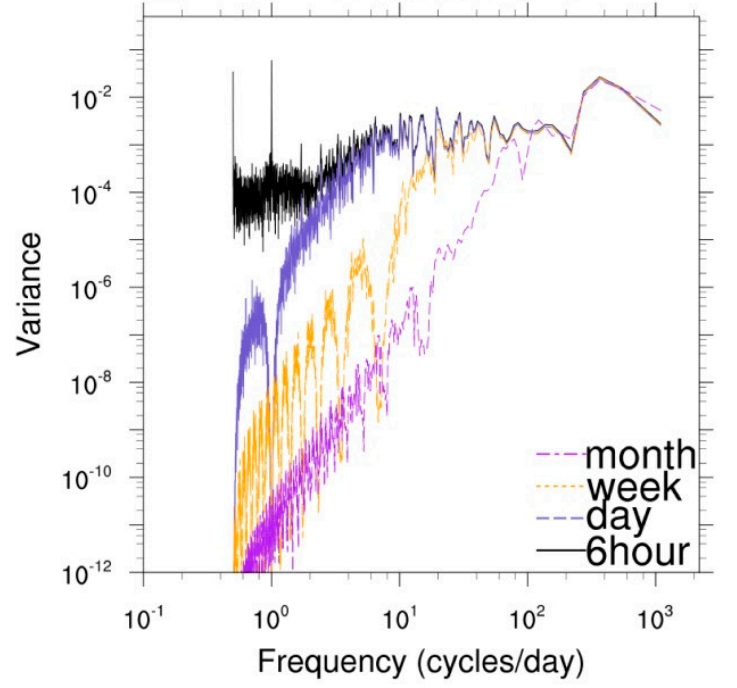

(b) Meridional wind stress $\left(80^{\circ} \mathrm{W}, 9^{\circ} \mathrm{S}\right)$

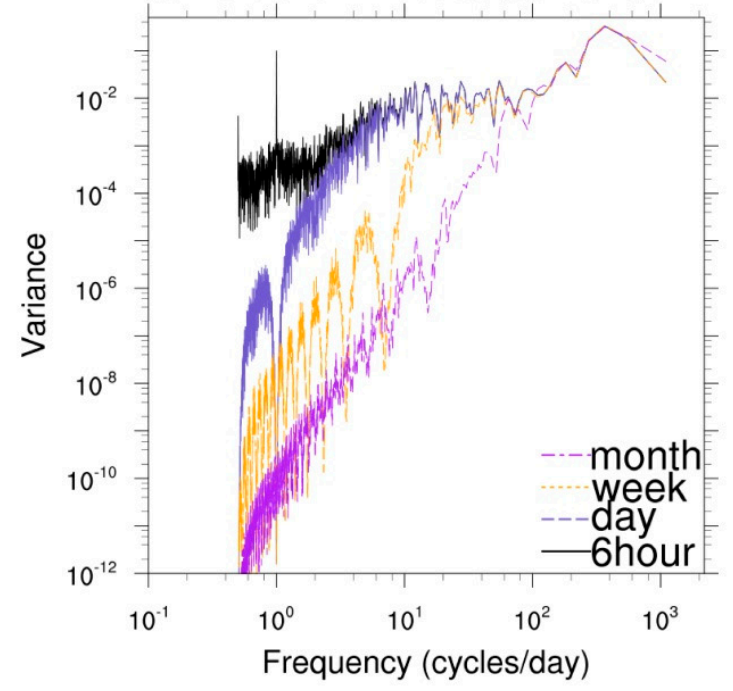

Figure 7. Frequency spectra of wind stress: (a) zonal wind stress and (b) meridional wind stress.

Figure 8 displays the vertical profile of the three-year mean vertical velocities along the Peruvian coast (averaged in the sample area). The Peruvian upwelling region, where the slope is steep, is distinct 
with the coastal upwelling over shallow shelves. In the upper $140 \mathrm{~m}$, the upwelling induced by wind is close to the theoretical studies of the upwelling cell, with the peak velocity at the bottom of the mixed layer $(25 \mathrm{~m})$. The vertical velocities ranging from 140 to $500 \mathrm{~m}$ were negative, indicating the presence of downwelling. All the sensitivity experiments could capture the structure of the vertical velocity. The differences of vertical velocities between the sensitivity experiments are shown in Figure $8 \mathrm{~b}$, which indicates that Exp_6hour had negative biases relative to Exp_day, Exp_week, and Exp_month. The biases between Exp_6hour and Exp_day were about 1-5\% of standard deviations of vertical velocities of Exp_6hour, and the biases between Exp_6hour and Exp_month were about 5-10\% of standard deviations. Most biases between Exp_6hour and Exp_week were negative, indicating that the high-frequency wind weakened the upwelling in the upper $140 \mathrm{~m}$ and strengthened the downwelling between 140 and $500 \mathrm{~m}$.
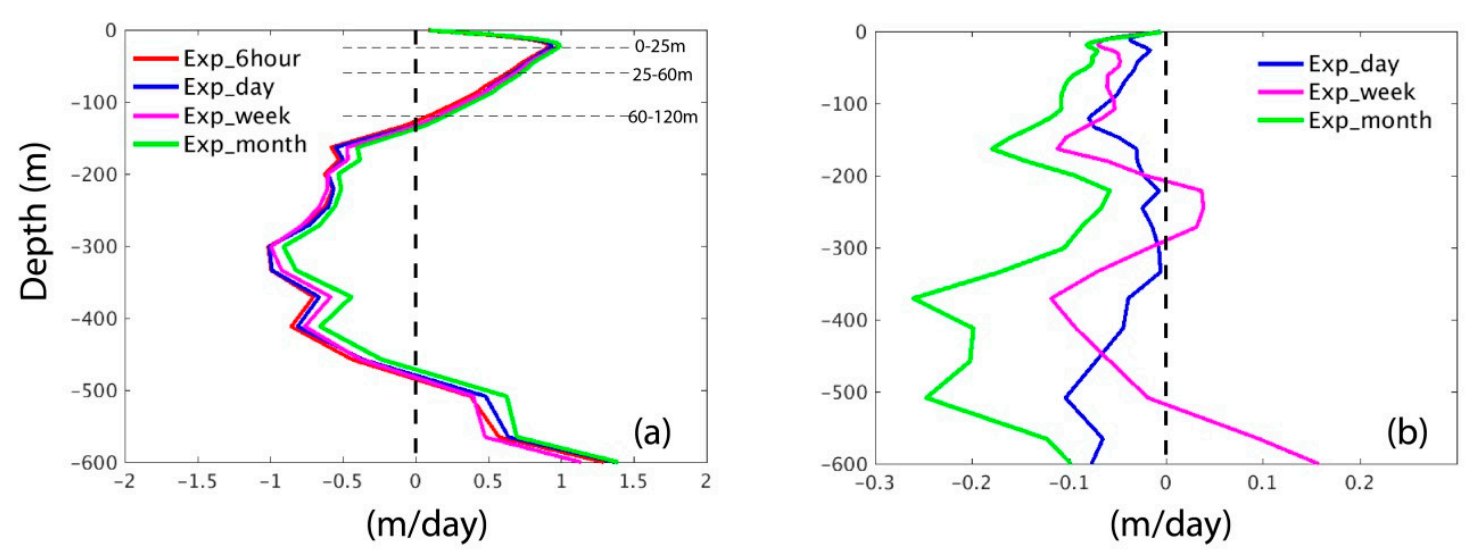

Figure 8. (a) Three-year mean vertical velocities profile and (b) the differences of the three-year mean vertical velocities between Exp_6hour and Exp_day, Exp_6hour and Exp_week, and Exp_6hour and Exp_month.

\section{Heat Budget Analysis in the Peruvian Upwelling}

To diagnose the oceanic processes leading to the temperature differences between Exp_6hour and Exp_day, the heat budget in the Peruvian upwelling was computed. The heat budget of the upper layer is expressed as:

$$
\frac{\partial T}{\partial t}=-u \frac{\partial T}{\partial x}-v \frac{\partial T}{\partial y}-w \frac{\partial T}{\partial z}+\frac{\partial}{\partial z}\left(K \frac{\partial T}{\partial z}\right)+\frac{\partial Q}{\partial z}
$$

The term on the left-hand side of Equation (1) is the temperature tendency (TT). The first three terms on the right-hand side of Equation (1) are referred to as zonal advection (ZADV), meridional advection (MADV), and vertical advection (VADV), respectively. The sum of these three terms is the advection term (ADV). The sum of the fourth term, vertical turbulent mixing, and the fifth term, the heat flux, is presented as DIF.

Figure 9a shows the time evolution of heat budgets above $25 \mathrm{~m}$ along the Peruvian coast. Driven by a persistent southeasterly wind, the cold water from upwelling was transported westward through an offshore Ekman transport. The ZADV and VADV led to a lower temperature. The DIF terms contributed to warmer water. Heat was absorbed from short-wave radiation at the surface and transported to deeper depth through vertical turbulent mixing. The positive MADV terms indicate that the water from the Humboldt Cold Current was warmer than the upwelling water. The temperature tendency was determined by heat advection (ADV). Below the mixed layer, the turbulent mixing and heat fluxes (DIF) weakened, the onshore zonal advection (ZADV) warmed the water, and vertical advection (VADV) led to cooler water (Figure 9d,g). 
$0-25 \mathrm{~m}$
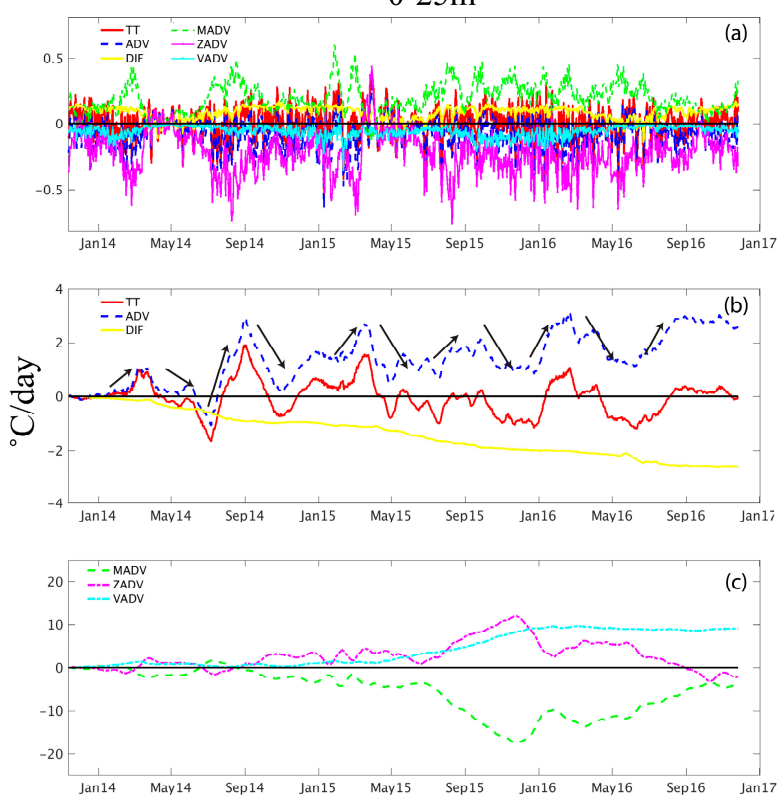

$25-60 \mathrm{~m}$
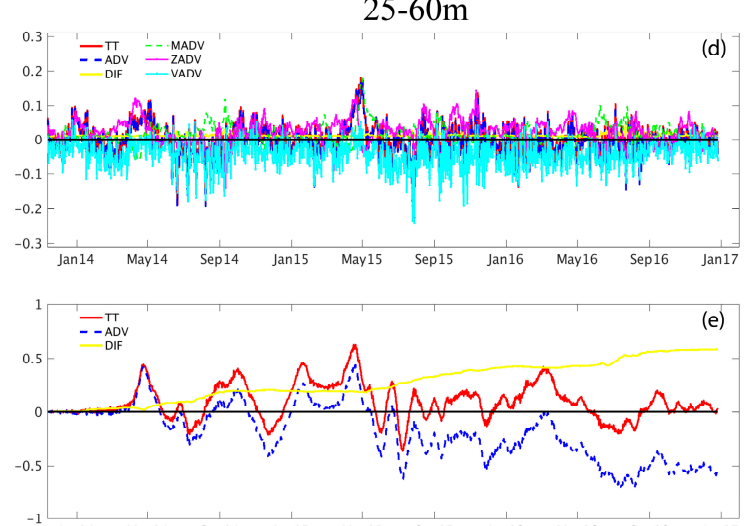

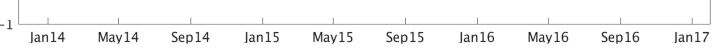

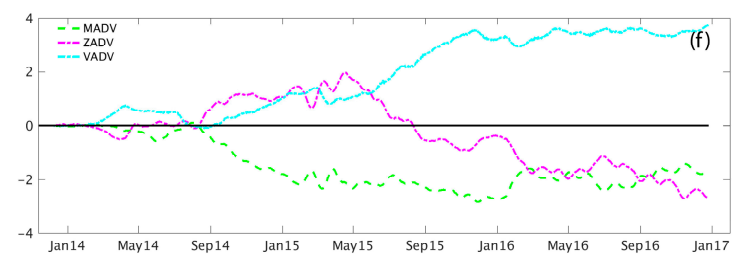

Time
$60-120 \mathrm{~m}$
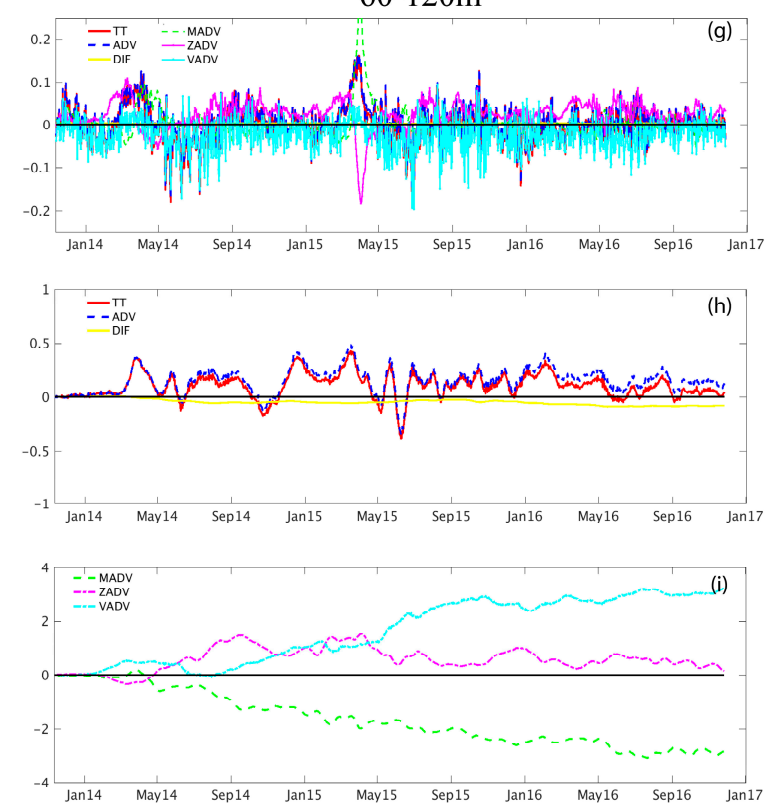

Figure 9. (a-c) Time evolution of upper-25-m layer heat budgets for Exp_day and the cumulative differences between Exp_6hour and Exp_day averaged in the Peruvian upwelling sampling area (Figure $1 \mathbf{b})$. (d-f) as in (a-c) except for the averaged subsurface $25-60 \mathrm{~m}$ layer; (g-i) as in (a-c) except for the averaged subsurface 60-120 m layer. ADV: advection; DIF: the sum of vertical turbulent mixing and heat flux; MADV: meridional advection; TT: temperature tendency; VADV: vertical advection; ZADV: zonal advection. 
The differences between Exp_6hour and Exp_day were similar to those between Exp_6hour and Exp_week, as well as Exp_6hour and Exp_month, so only the accumulative differences between Exp_6hour and Exp_day are displayed (Figure 9b,c,e,f,h,i). The positive (negative) slope indicates the process to generate the positive (negative) temperature anomaly tendency during this period of time. The temperature changes in the three layers were determined by different mechanisms of wind effect (shown in Figure 8a). The temperature differences in the mixed layer $(0-25 \mathrm{~m})$ between Exp_6hour and Exp_day were mainly due to the effect of advection (ADV), which showed seasonal variation, often with positive differences in austral spring and autumn (Figure 9b). The enhanced mixing (DIF) due to high-frequency wind brought larger amounts of cold water to the surface, against the effect of advection. When the warming of ADV is weak (strong), the temperature showed cold (warm) biases. The positive differences of the advection terms were due to zonal advection (ZADV) and vertical advection (VADV), while the meridional advection (MADV) reduced the warm temperature differences (Figure 9c). Under the mixed layer, enhanced turbulent mixing contributed to the temperature warming at depths of 25-60 m (Figure 9e). The effect of mixing could be neglected below the depths of $60 \mathrm{~m}$, while vertical advection dominated the variability of temperature tendency differences (Figure $9 \mathrm{~h}$ ). The VADV was the primary term leading to positive temperature differences here (Figure 9f,h).

Due to the biases in the CFSRv2 surface fluxes, heat correction is a common practice in the regional ocean simulation to avoid long-term drifts in temperature. Turning off the heat correction in the sensitivity experiments is done to focus on the effect of high-frequency wind. We performed the same sensitivity experiments with heat correction turned on. The results showed that heat correction could decrease the sensitivity of upwelling to high-frequency wind, but did not change the qualitative conclusions. This is consistent with the findings of Lee and Liu [9], which compared the impacts of high-frequency wind sampling on temperature and mixed-layer depth with and without heat correction, and showed that the heat correction did not change the conclusions.

\section{Summary}

In this paper, the impact of high-frequency wind on the Peruvian upwelling from 2014 to 2016 was studied by conducting four sensitivity experiments, respectively forced by six-hourly, daily, weekly, and monthly wind forcing. An effect of high-frequency wind stresses was warming along the Peruvian coast, and this warming effect reduced as the frequency of wind forcing decreased. The temperature differences in the mixed layer varied seasonally, often with warm biases in austral autumn (April to May) and cold biases in austral spring (September to October). The temperature under the mixed layer displayed warm biases due to high-frequency wind most of the time.

The comparison of the sensitivity experiments with wind forcing of different temporal scales revealed that eliminating the high-frequency wind led to the weakening of the high-frequency vertical velocity fluctuations. The signals of near-inertial, weekly, and bi-weekly (periods $2-3$ days, 5-6 days, and 10-18 days) fluctuations nearly disappeared for the cases using weekly wind stresses. The synoptic-scale wind stress supplied the most energy to the high-frequency waves in the ocean. The high-frequency winds produced negative biases on the mean state of vertical velocities, causing the upwelling above $140 \mathrm{~m}$ to weaken and the downwelling under $140 \mathrm{~m}$ to strengthen. An important implication of these results is that high-frequency wind forcing must be considered in order to properly model and predict the Peruvian upwelling system, and if a coupled atmosphere-ocean modeling system is used, the data exchange (or coupling) frequency must be higher than daily exchanges.

The heat budget analysis revealed that the warm biases in temperature due to high-frequency winds were mainly through the variation of the zonal and vertical heat advections. Heat advection contributed to the seasonal variation of temperature biases. Turbulent mixing tended to damp the effect of heat advection, and varied with depth. The enhanced turbulent mixing due to high-frequency wind largely cooled the water in the mixed layer $(0-25 \mathrm{~m})$ by bringing greater amounts of cold water to the surface, and warmed the water in the layer from 25 to $60 \mathrm{~m}$, under the mixed layer. Deeper than $60 \mathrm{~m}$, the influence of the turbulent mixing could be ignored. 
Author Contributions: Conceptualization: L.X.; Modeling work: L.W.; Validation: G.H., S.J.; Formal analysis: L.X. and L.W.; Writing—original draft: L.W.; Writing—review and editing: L.X., L.W., G.H. and S.J.; Project administration and supervision: G.H. and S.J.

Funding: This research was supported by the NSFC-Shandong Joint Fund for Marine Ecology and Environmental Sciences (U1606404); and The Youth Talent Support Program of the Laboratory for Marine Ecology and Environmental Science, Pilot National laboratory for Marine Science and Technology (Qingdao) (LMEES-YTSP-2018-02-03).

Acknowledgments: We are thankful for the support provided by the China Scholarship Council during the visit of Linhui Wang to North Carolina State University. We thank three anonymous reviewers for their meaningful comments.

Conflicts of Interest: The authors declare no conflict of interest.

\section{References}

1. Chavez, F.P.; Messié, M. A comparison of Eastern Boundary Upwelling Ecosystems. Prog. Oceanogr. 2009, 83, 80-96. [CrossRef]

2. Slingo, J.; Inness, P.; Neale, R.; Woolnough, S.; Yang, G. Scale interactions on diurnal to seasonal timescales and their relevance to model systematic errors. Ann. Geophys. Italy 2003, 46, 139-155.

3. Hunter, E.; Chant, R.; Bowers, L.; Glenn, S.; Kohut, J. Spatial and temporal variability of diurnal wind forcing in the coastal ocean. Geophys. Lett. 2007, 34, L03607. [CrossRef]

4. Kamenkovich, I.V. Role of daily surface forcing in setting the temperature and mixed layer structure of the Southern Ocean. J. Geophys. Res. 2005, 110, C07006. [CrossRef]

5. Yu, Y.; Gao, H.; Shi, J.; Guo, X.; Liu, G. Diurnal Forcing Induces Variations in Seasonal Temperature and Its Rectification Mechanism in the Eastern Shelf Seas of China. J. Geophys. Res. 2017, 122, 9870-9888. [CrossRef]

6. Sui, C.; Li, X.; Rienecker, M.M.; Lau, K.; Laszlo, I.; Pinker, R.T. The Role of Daily Surface Forcing in the Upper Ocean over the Tropical Pacific: A Numerical Study. J. Clim. 2003, 16, 756-766. [CrossRef]

7. Zhou, S.; Zhai, X.; Renfrew, I.A. The Impact of High-Frequency Weather Systems on SST and Surface Mixed Layer in the Central Arabian Sea. J. Geophys. Res. 2018, 123, 1091-1104. [CrossRef]

8. Thushara, V.; Vinayachandran, P.N. Impact of diurnal forcing on intraseasonal sea surface temperature oscillations in the Bay of Bengal. J. Geophys. Res. 2014, 119, 8221-8241. [CrossRef]

9. Lee, T.; Liu, W.T. Effects of high-frequency wind sampling on simulated mixed layer depth and upper ocean temperature. J. Geophys. Res. 2005, 110, C05002. [CrossRef]

10. Espinoza-Morriberón, D.; Echevin, V.; Colas, F.; Tam, J.; Ledesma, J.; Vásquez, L.; Graco, M. Impacts of El Niño events on the Peruvian upwelling system productivity. J. Geophys. Res. 2017, 122, 5423-5444. [CrossRef]

11. Dewitte, B.; Vazquez-Cuervo, J.; Goubanova, K.; Illig, S.; Takahashi, K.; Cambon, G.; Purca, S.; Correa, D.; Gutierrez, D.; Sifeddine, A.; et al. Change in El Niño flavours over 1958-2008: Implications for the long-term trend of the upwelling off Peru. Deep Sea Res. Part II 2012, 77-80, 143-156. [CrossRef]

12. Woodson, C.B.; Eerkes-Medrano, D.I.; Flores-Morales, A.; Foley, M.M.; Henkel, S.K.; Hessing-Lewis, M.; Jacinto, D.; Needles, L.; Nishizaki, M.T.; Leary, J.O.; et al. Local diurnal upwelling driven by sea breezes in northern Monterey Bay. Cont. Shelf Res. 2007, 27, 2289-2302. [CrossRef]

13. Reyes-Mendoza, O.; Mariño-Tapia, I.; Herrera-Silveira, J.; Ruiz-Martínez, G.; Enriquez, C.; Largier, J.L. The Effects of Wind on Upwelling off Cabo Catoche. J. Coast. Res. 2015, 32, 638-650. [CrossRef]

14. Walter, R.K.; Stastna, M.; Woodson, C.B.; Monismith, S.G. Observations of nonlinear internal waves at a persistent coastal upwelling front. Cont. Shelf Res. 2016, 117, 100-117. [CrossRef]

15. Lerczak, J.A.; Hendershott, M.C.; Winant, C.D. Observations and modeling of coastal internal waves driven by a diurnal sea breeze. J. Geophys. Res. 2001, 106, 19715-19729. [CrossRef]

16. Orlić, M.; Beg Paklar, G.; Dadić, V.; Leder, N.; Mihanović, H.; Pasarić, M.; Pasarić, Z. Diurnal upwelling resonantly driven by sea breezes around an Adriatic island. J. Geophys. Res. 2011, 116, C09025. [CrossRef]

17. Shchepetkin, A.F.; McWilliams, J.C. The regional oceanic modeling system (ROMS): A split-explicit, free-surface, topography-following-coordinate oceanic model. Ocean Model. 2005, 9, 347-404. [CrossRef]

18. Amante, C.; Eakins, B.W. ETOPO1 1 Arc-Minute Global Relief Model: Procedures, Data Sources and Analysis. NOAA Tech. Memo. NESDIS NGDC-24 2018. [CrossRef] 
19. Haidvogel, D.B.; Arango, H.G.; Hedstrom, K.; Beckmann, A.; Malanotte-Rizzoli, P.; Shchepetkin, A.F. Model evaluation experiments in the North Atlantic Basin: Simulations in nonlinear terrain-following coordinates. Dyn. Atmos. Oceans. 2000, 32, 239-281. [CrossRef]

20. Gordon, C.; Corry, R.A. A model simulation of the seasonal cycle in the tropical Pacific Ocean using climatological and modeled surface forcing. J. Geophys. Res. 1991, 96, 847-864. [CrossRef]

21. Chen, D.; Liu, W.T.; Zebiak, S.E.; Cane, M.A.; Kushnir, Y.; Witter, D. Sensitivity of the tropical Pacific Ocean simulation to the temporal and spatial resolution of wind forcing. J. Geophys. Res. 1999, 104, 11261-11271. [CrossRef]

22. Vargas, G.; Pantoja, S.; Rutllant, J.A.; Lange, C.B.; Ortlieb, L. Enhancement of coastal upwelling and interdecadal ENSO-like variability in the Peru-Chile Current since late 19th century. Geophys. Res. Lett. 2007, 34, L13607. [CrossRef]

23. Danioux, E.; Klein, P. A Resonance Mechanism Leading to Wind-Forced Motions with a 2 f Frequency. J. Phys. Oceanogr. 2008, 38, 2322-2329. [CrossRef]

24. Smith, R.L. Poleward propagating perturbations in currents and sea levels along the Peru Coast. J. Coast. Res. 1978, 83, 6083-6092. [CrossRef]

25. Dewitte, B.; Illig, S.; Renault, L.; Goubanova, K.; Takahashi, K.; Gushchina, D.; Mosquera, K.; Purca, S. Modes of covariability between sea surface temperature and wind stress intraseasonal anomalies along the coast of Peru from satellite observations (2000-2008). J. Geophys. Res. 2011, 116, C04028. [CrossRef]

26. Pietri, A.; Echevin, V.; Testor, P.; Chaigneau, A.; Mortier, L.; Grados, C.; Albert, A. Impact of a coastal-trapped wave on the near-coastal circulation of the Peru upwelling system from glider data. J. Geophys. Res. 2014, 119, 2109-2120. [CrossRef]

27. Jouanno, J.; Pallàs-Sanz, E.; Sheinbaum, J. Variability and Dynamics of the Yucatan Upwelling: High-Resolution Simulations. J. Geophys. Res. 2018, 123, 1251-1262. [CrossRef]

(C) 2019 by the authors. Licensee MDPI, Basel, Switzerland. This article is an open access article distributed under the terms and conditions of the Creative Commons Attribution (CC BY) license (http://creativecommons.org/licenses/by/4.0/). 